\title{
TERT Promoter Mutations in Penile Squamous Cell Carcinoma: High Frequency in Non-HPV-related Type and Association With Favorable Clinicopathologic Features
}

\section{Sang Kyum Kim}

Yonsei University College of Medicine

Jang-Hee Kim

Ajou University School of Medicine

Jae-Ho Han

Ajou University School of Medicine

Nam Hoon Cho

Yonsei University College of Medicine

Se Joong Kim

Ajou University School of Medicine

Sun II Kim

Ajou University School of Medicine

Seol Ho Choo

Ajou University School of Medicine

Ji Su Kim

Ajou University School of Medicine

Bumhee Park

Ajou University School of Medicine and Ajou University Medical center

Ji Eun Kwon ( $\nabla$ kjefullup@aumc.ac.kr)

Ajou University School of Medicine

Research

Keywords: TERT promoter, penile cancer, human papillomavirus

Posted Date: July 17 th, 2020

DOI: https://doi.org/10.21203/rs.3.rs-43639/v1

License: (c) (i) This work is licensed under a Creative Commons Attribution 4.0 International License.

Read Full License 
Version of Record: A version of this preprint was published at Journal of Cancer Research and Clinical Oncology on February 26th, 2021. See the published version at https://doi.org/10.1007/s00432-02103514-9. 


\section{Abstract}

\section{Background}

Penile carcinoma is a rare malignant neoplasm and its molecular pathogenetic mechanism is largely unknown. Telomerase reverse transcriptase (TERT) promoter mutations have been detected in several types of human malignancies, including malignant melanoma, non-melanoma skin cancer, thyroid carcinoma, glioma, and bladder carcinoma. However, TERT-p mutation in penile squamous cell carcinoma (SCC) has not been investigated to date. The aim of this study was to investigate the presence of TERT promoter mutations in penile squamous cell carcinomas and their associations with clinicopathologic features.

\section{Methods}

Sanger sequencing was performed to detect TERT promoter mutations in formalin-fixed paraffinembedded tissue samples from 37 cases of penile SCC, 16 cases of cutaneous SCC, and 4 cases of nonneoplastic penile/skin tissue. The expression of $\mathrm{p} 16$ and Ki67 were investigated by immunohistochemistry. Associations of TERT promoter mutation with clinicopathological factors, immunohistochemical results, and clinical outcome were statistically analyzed.

\section{Results}

Recurrent TERT promoter mutations were identified in 18 of $37(48.6 \%)$ penile SCCs, including all three carcinoma in situ cases. TERT promoter mutations were significantly more frequent in non-human papilloma virus (HPV)-related penile SCC types based on both histologic classification and p16 $6^{\text {INK4a }}$ immunoreactivity. Furthermore, TERT promoter mutation was associated with a low histologic grade, low mitotic count, absence of necrosis, and low Ki67/MIB-1 labelling index. Univariate Cox regression analysis and Kaplan-Meier analysis with the log-rank test indicated that TERT promoter mutation was a favorable factor for disease-free survival.

\section{Conclusions}

Our study shows TERT-p mutations are the most frequent somatic mutations in penile SCC. In addition, TERT-p mutations are far more frequent in non-HPV-related penile SCC, indicating that in case of nonHPV-related penile SCC, TERT-p mutations may have a role in tumorigenesis distinct from HPV-related penile SCC.

\section{Background}

Penile carcinoma is a rare malignant neoplasm with an incidence of 1 to 4 per 100,000 in developing countries and is even rarer in developed countries [1]. Squamous cell carcinoma (SCC) and its histologic variants account for approximately $95 \%$ of all cases of penile carcinoma [2]. Pathologically, penile carcinomas are classified into two distinct groups: human papilloma virus (HPV)-related type and non- 
HPV-related type, depending on clinicopathologic characteristics and an association with HPV infection [3]. HPV high-risk (HPV-HR) DNA is detected in $20-80 \%$ of penile carcinomas, and plays a role in the carcinogenesis of HPV-related penile SCC [4]. The detection rates of HPV DNA vary depending on histologic subtypes [5]. Unlike SCC of the uterine cervix, which is caused by HPV in $100 \%$ of cases, only about $1 / 3$ to $1 / 2$ of penile carcinomas are caused by transforming HPV infection. The non-HPV-related type of penile SCC develops in the background of chronic inflammatory skin diseases such as lichen sclerosus and lichen planus. HPV-HR16 is known to be the most prevalent HPV DNA type in HPV-related penile SCC [1]. The viral oncogenes of HPV, E6 and E7, bind to the tumor suppressor proteins p53 and RB, respectively, leading to their inactivation, thereby affecting the cell cycle and apoptosis, resulting in unchecked replication of DNA and continued cell proliferation [4]. Consequently, p16 ${ }^{\text {INK4a }}$ protein, a cyclindependent kinase inhibitor, accumulates, which can be identified by $16^{\text {INK4a }}$ immunohistochemistry [6].

Along with technological advances in the past decade, genetic alterations in cancers have been extensively disclosed, ushering in a new era of precision medicine in cancer treatment [7]. However, this has not been the case for penile cancer, as the underlying molecular pathogenesis has yet to be elucidated, which is most likely due to the rarity of penile SCC. Accordingly, no standardized treatment or personalized medicine has yet been established for penile cancer [8].

The telomerase reverse transcriptase (TERT) gene encodes the catalytic subunit of telomerase that is responsible for telomere lengthening at chromosomal ends [9]. Normal somatic cells and benign tumor cells lack telomerase activity, whereas telomerase is active in germ cells and stem cells of self-renewing tissues [10], and is found to be reactivated in up to $90 \%$ of cancer cells [11]. Reactivation of telomerase maintains the telomere length, which enables cancer cells to evade senescence resulting from telomere shortening. Novel recurrent somatic mutations in the core promoter region of TERT were recently identified in $\sim 70 \%$ of melanoma samples examined by next-generation sequencing, which have now become the most frequently detected mutations in malignant melanoma [12, 13]. Subsequently, these mutations were also detected at high frequency in several other human malignancies, including thyroid carcinoma, glioma, bladder carcinoma, hepatocellular carcinoma, and various types of non-melanoma skin cancers such as SCC and basal cell carcinoma [14-21]. By contrast, TERT promoter (TERT-p) mutations have not been detected or have been detected at very low frequency in malignant tumors of other organs [22-24]. In addition, the clinical relevance of these mutations has been highlighted based on significant associations with poor patient outcome or adverse clinicopathologic parameters in various cancers [25-30]. TERT-p mutations create de novo binding sites for E-twenty-six (ETS) transcription factors (CCGGAA) within the TERT-p region. An in vitro luciferase assay also showed that these mutations resulted in a 2-4-fold increase of TERT promoter activity [13]. Despite continuing research on $T E R T$-p mutation in human cancers, including a recent study describing the varying frequency of $T E R T-\mathrm{p}$ mutation in SCCs arising from various organs [23], TERT-p mutation in penile SCC has not been investigated to date.

Therefore, the aim of the present study was to investigate the presence of TERT-p mutations in penile SCC, and their associations with clinicopathologic parameters, along with p16 ${ }^{\text {INK4a }}$ and Ki-67/MIB-1 
expression.

\section{Methods}

\section{Case selection}

Formalin-fixed, paraffin-embedded tissues from 37 surgically resected penile carcinomas were retrieved from the archives of the Department of Pathology of Ajou University School of Medicine (23 cases) and the Department of Pathology of Yonsei University College of Medicine (14 cases) based on the availability of tissue blocks or slides for histopathologic analyses and DNA extraction. Among the 37 cases, there were three cases of carcinoma in situ (CIS) included. In addition, 16 cases of cutaneous SCC and four samples of non-tumor skin or penile tissue were used as positive and negative controls, respectively, for TERT-p sequencing.

\section{DNA extraction and direct sequencing}

The tumors were manually dissected from $10-\mu \mathrm{m}$ sections of formalin-fixed, paraffin-embedded tissues. Genomic DNA was extracted using the QIAamp kit (Qiagen, Hilden, Germany) according to the manufacturer's instructions. Polymerase chain reaction (PCR) amplification of the TERT promoter region was performed using the primer pair h TERT_F (CAC CCG TCC TGC CCC TTC ACC TT)/h TERT_R (CAG CGC TGC CTG AAA CTC), generating an expected 304-bp product. The cycling condition for PCR amplification was $95^{\circ} \mathrm{C}$ for 2 min for denaturation, and 35 cycles of $95^{\circ} \mathrm{C}$ denaturation for $30 \mathrm{~s}, 60^{\circ} \mathrm{C}$ annealing for $30 \mathrm{~s}$, and $72^{\circ} \mathrm{C}$ elongation for $40 \mathrm{~s}$. PCR products were confirmed by gel electrophoresis. Direct sequencing of both strands was performed using a BigDye terminator v3.1 cycle sequencing kit (Applied Biosystems, Foster City, CA, USA) on an ABI 3500XL genetic analysis system (Applied Biosystems).

\section{Clinicopathologic features}

All hematoxylin and eosin-stained slides from the tumors were reviewed independently by two pathologists who were blinded to other clinical and genetic information. Clinical data were collected from the medical records. The factors investigated were as follows: histologic subtype, grade, presence and type of penile intraepithelial neoplasia (PeIN), lymphovascular invasion, perineural invasion, ulceration, tumor thickness, necrosis, mitotic count, koilocytosis, acantholysis, tumor-infiltrating lymphocytes, intraepithelial neutrophilic microabscess, peripheral tumor budding [31], tumor size, gross type, patient age, stage, lymph node or distant metastasis, and patient survival (Fig. 1). Histologic subtype was determined according to the World Health Organization classification 2016 into HPV-related type and non-HPV related type [5]. A mixed HPV-related and non-HPV-related type was considered a HPV-related type for statistical analyses. The mitotic count was calculated from 10 contiguous high-power fields located in the most mitotically active tumor region.

\section{Immunohistochemistry for $\mathrm{p} 16^{\mathrm{INK} 4 \mathrm{a}}$ and Ki-67}


Immunohistochemical staining for $\mathrm{p} 16^{\mathrm{INK} 4 \mathrm{a}}$ and $\mathrm{Ki}-67$ was performed on one representative block of all samples on a BenchMark XT autostainer (Ventana Medical Systems, Tucson, AZ, USA) according to the manufacturer's protocol using a ready-to-use mouse monoclonal p16 ${ }^{\text {INK4a }}$ antibody (CINtec p16 Histology, clone E6H4, Sedona, USA) and an anti-human mouse monoclonal Ki-67 antibody (1:100, clone MIB-1, DAKO, Copenhagen, Denmark). Only strong continuous staining of p16 $6^{\text {INK4a }}$ was considered positive. Weak or spotty, patchy, and discontinuous staining was considered negative. [32, 33] For the Ki67 stain, any distinct nuclear staining was recorded as positive. The Ki-67 (MIB-1) labeling index, defined as the percentage of positively stained tumor cells, was measured by computer-assisted manual counting at least 1000 tumor nuclei from the area of maximal labeling using Image-Pro Plus 4.5 software.

\section{Statistical analyses}

Statistical analyses were performed using SPSS v22.0 (SPSS Inc., Chicago, IL, USA). The relation between TERT-p mutation and clinicopathologic parameters was evaluated using the Chi-square test or Fisher's exact test and the Mann-Whitney $U$ test for categorical and continuous variables, respectively. Kaplan-Meier survival analysis and the log-rank test were used to analyze the prognostic effect of TERT-p mutation in terms of both disease-free survival (DFS) and overall survival (OS). Univariate and multivariate regression analyses were performed using the Cox proportional hazards model. A P-value< 0.05 was considered statistically significant. We conducted a power analysis for determining an appropriate sample size in Cox proportional Hazard Regression analysis using PASS v14.0.14.

\section{Results}

\section{Study cohort}

The age at diagnosis for the included patients was 65.97 \pm 12.18 years (range $40-87$ years). Of the 37 penile SCCs, 17 were HPV-related type and 20 were non-HPV-related type. Follow-up data were available for all 37 cases, and the follow-up period ranged from 4 months to 13.8 years (median 80.47 months). Seven patients died of the disease. (Table 1). 
Table 1

Summary of patient characteristics

\section{Characteristics}

Age at diagnosis (years)

Mean \pm SD

Range

Tumor size $(\mathrm{cm})$

Mean \pm SD

Range

Histologic type (No. of patient)

HPV-related

Non-HPV-related

AJCC Stage (No. of patient)

।

II

III

IV

Grade (No. of patient)

1 (well differentiated)

2 (moderately differentiated)

3 (poorly differentiated)

Gross type (No. of patient)

Superficial spreading ${ }^{a}$

Verrucous

Vertical

Follow-up duration (month)

Median

Range
$\mathbf{N}=\mathbf{3 7}$

$65.97 \pm 12.18$

40-87

$3.59 \pm 2.43$

1-14

20

8

18

5

6

17

10

9

18

8

13

16

80.47

4-166

SD, standard deviation; AJCC, the American Joint Committee on Cancer; ${ }^{\text {a }}$ the three cases of carcinoma in situ were included. 


\begin{tabular}{|ll|}
\hline Characteristics & $\mathbf{N}=\mathbf{3 7}$ \\
\hline Metastasis (No. of patient) & 10 \\
Lymph node & 7 \\
Distant metastasis & 3 \\
Bone & 4 \\
Lung & 22 \\
\hline Clinical outcome (No. of patient) & 7 \\
Alive & 5 \\
Died of disease & \\
Died of other cause & \\
\hline $\begin{array}{l}\text { SD, standard deviation; AJCC, the American Joint Committee on Cancer; }{ }^{\text {a }} \text { the three cases of } \\
\text { carcinoma in situ were included. }\end{array}$ \\
\hline
\end{tabular}

\section{TERT- $\mathrm{p}$ mutations are frequent in penile SCC}

Of the 37 penile SCCs, including the three cases of CIS, 18 cases (48.6\%) harbored TERT-p mutations, including c. $-146 \mathrm{C}>\mathrm{T}, \mathrm{c} .-124 \mathrm{C}>\mathrm{T}$, and c. $-124 \mathrm{C}>\mathrm{A}$. All three $\mathrm{ClS}$ tumors harbored the c. $-146 \mathrm{C}>\mathrm{T}$ mutation. Ten (63\%) of the 16 skin SCCs had TERT-p mutations, which were located at positions c. $-146 \mathrm{C}$ $>$ T, c. $-124 \mathrm{C}>\mathrm{T}$, and c.-139_-138CC > TT. The four negative control samples (non-neoplastic penile or skin tissue) all showed the wild-type TERT-p sequence (Table 2). 
Table 2

TERT promoter mutations identified in penile squamous cell carcinoma and control tissues

\begin{tabular}{|c|c|c|c|c|c|c|c|}
\hline \multirow[t]{2}{*}{ Tissue } & \multirow{2}{*}{$\begin{array}{l}\mathbf{N} \\
(\%)\end{array}$} & \multicolumn{5}{|c|}{ TERT-p mutant } & \multirow{2}{*}{$\begin{array}{l}\text { TERT-p } \\
\text { wild }\end{array}$} \\
\hline & & Overall & $\begin{array}{l}\text { C. }-146 \\
C>T\end{array}$ & $\begin{array}{l}\text { C. }-124 \\
C>T\end{array}$ & $\begin{array}{l}\text { C. }-124 \\
C>A\end{array}$ & $\begin{array}{l}\text { c. }-139-138 \mathrm{CC} \\
>\text { >TT }\end{array}$ & \\
\hline \multirow{2}{*}{$\begin{array}{l}\text { Penile SCC } \\
\text { invasive }\end{array}$} & 34 & 15 & 11 & 3 & 1 & 0 & 19 \\
\hline & $(100 \%)$ & $(44.1 \%)$ & $(32.3 \%)$ & (8.8\%) & $(2.9 \%)$ & & (55.8\%) \\
\hline \multirow[t]{2}{*}{ Penile SCC in situ } & 3 & 3 & 3 & 0 & 0 & 0 & 0 \\
\hline & $(100 \%)$ & $(100 \%)$ & $(100 \%)$ & & & & \\
\hline \multirow{2}{*}{$\begin{array}{l}\text { Penile SCC in situ } \\
\text { and invasive }\end{array}$} & 37 & 18 & 14 & 3 & 1 & 0 & 19 \\
\hline & $(100 \%)$ & $(48.6 \%)$ & $(37.8 \%)$ & (8.1\%) & $(2.7 \%)$ & & (55.8\%) \\
\hline \multirow[t]{2}{*}{ Skin SCC } & 16 & 10 & 8 & 1 & 0 & 1 & 6 \\
\hline & $(62.5 \%)$ & $(63 \%)$ & $(50.0 \%)$ & $(6.2 \%)$ & & $(6.2 \%)$ & $(37 \%)$ \\
\hline Pen $N T^{a}$ & 2 & 0 & 0 & 0 & 0 & 0 & 2 \\
\hline \multirow{3}{*}{ Skin $\mathrm{NT}^{\mathrm{a}}$} & 2 & 0 & 0 & 0 & 0 & 0 & $(100 \%)$ \\
\hline & & & & & & & 2 \\
\hline & & & & & & & $(100 \%)$ \\
\hline \multicolumn{8}{|c|}{ No, number; Pen, penile; NT, non-tumor tissue; SCC, squamous cell carcinoma } \\
\hline \multicolumn{8}{|l|}{ anegative control } \\
\hline
\end{tabular}

\section{Correlation of TERT-p mutation status with clinicopathologic parameters}

To explore potential associations between TERT-p mutation status and clinicopathologic parameters, statistical analyses were performed on the 24 invasive SCCs, excluding the three CIS cases. TERT-p mutations were more frequent in non-HPV-related type than in HPV-related type penile SCCs (13/20, $86.7 \%$ vs $2 / 14,13.3 \% ; p=0.005)$. In line with this finding, TERT-p mutations correlated with the presence of differentiated PeIN, which is a precursor lesion associated with non-HPV-related type penile SCC $(\mathrm{p}=$ 0.005). TERT-p mutations were also more frequent in tumors with a lower histologic grade $(p=0.036)$, lower mitotic activity $(p=0.001)$, absence of necrosis $(p=0.045)$, larger tumor size $(p=0.045)$, and absence of lymph node or distant metastasis $(p=0.020)($ Table 3$)$. 
Table 3

Associations between TERT promoter mutation and clinicopathologic parameters in 34 patients with invasive penile squamous cell carcinoma

\begin{tabular}{|c|c|c|c|}
\hline Parameters & $\begin{array}{l}\text { TERT-p wild } \\
\mathrm{N}=19\end{array}$ & $\begin{array}{l}\text { TERT-p mutant } \\
\mathrm{N}=15\end{array}$ & P-value \\
\hline Histologic subtype & $12(63.2)$ & $2(13.3)$ & 0.005 \\
\hline HPV-related & $7(36.8)$ & $13(86.7)$ & \\
\hline \multicolumn{4}{|l|}{ Non-HPV-related } \\
\hline Histologic grade & $3(15.8)$ & $7(46.7)$ & 0.036 \\
\hline WD & $5(26.3)$ & $4(26.7)$ & \\
\hline MD & $11(57.9)$ & $4(26.7)$ & \\
\hline \multicolumn{4}{|l|}{ PD } \\
\hline Acantholysis & $15(78.9)$ & $10(66.7)$ & 0.462 \\
\hline Absent & $4(21.1)$ & $5(33.3)$ & \\
\hline \multicolumn{4}{|l|}{ Present } \\
\hline Lymphovascular invasion & $10(52.6)$ & $10(66.7)$ & 0.409 \\
\hline Absent & $9(47.4)$ & $5(33.3)$ & \\
\hline \multicolumn{4}{|l|}{ Present } \\
\hline Perineural invasion & $13(68.4)$ & $12(80.0)$ & 0.697 \\
\hline Absent & $6(31.6)$ & $3(20.0)$ & \\
\hline \multicolumn{4}{|l|}{ Present } \\
\hline Koilocytosis & $10(52.6)$ & $5(33.3)$ & 0.260 \\
\hline Absent & $9(47.4)$ & $10(66.7)$ & \\
\hline \multicolumn{4}{|l|}{ Present } \\
\hline Mitosis (/HPF) & $9.02 \pm 6.92$ & $2.68 \pm 1.71$ & 0.001 \\
\hline Mean \pm SD & $10(52.6)$ & $15(100)$ & 0.002 \\
\hline$\leq 8$ & $9(47.4)$ & $0(0)$ & \\
\hline$>8$ & & & \\
\hline
\end{tabular}

HPV, human papilloma virus; HPF, high-power field; WD, well-differentiated; MD, moderately differentiated; PD, poorly differentiated; AJCC, the American Joint Committee on Cancer; LN, lymph node; PelN, penile intraepithelial neoplasia 


\begin{tabular}{|c|c|c|c|}
\hline Parameters & $\begin{array}{l}\text { TERT-p wild } \\
\mathrm{N}=19\end{array}$ & $\begin{array}{l}\text { TERT-p mutant } \\
\mathrm{N}=15\end{array}$ & P-value \\
\hline $\begin{array}{l}\text { Tumor thickness }(\mathrm{cm}) \\
<1.2 \\
\geq 1.2\end{array}$ & $\begin{array}{l}11(57.9) \\
8(42.1)\end{array}$ & $\begin{array}{l}6(40.0) \\
9(60.0)\end{array}$ & 0.300 \\
\hline $\begin{array}{l}\text { Necrosis } \\
\text { Absent } \\
\text { Present }\end{array}$ & $\begin{array}{l}7(36.8) \\
12(63.2)\end{array}$ & $\begin{array}{l}11(73.3) \\
4(26.7)\end{array}$ & 0.045 \\
\hline $\begin{array}{l}\text { Tumor infiltrating lymphocytes } \\
\text { Absent to non-brisk } \\
\text { Brisk }\end{array}$ & $\begin{array}{l}11(57.9) \\
8(42.1)\end{array}$ & $\begin{array}{l}11(73.3) \\
4(26.7)\end{array}$ & 0.476 \\
\hline $\begin{array}{l}\text { Ulceration } \\
\text { Absent } \\
\text { Present }\end{array}$ & $\begin{array}{l}8(42.1) \\
11(57.9)\end{array}$ & $\begin{array}{l}9(60.0) \\
6(40.0)\end{array}$ & 0.300 \\
\hline $\begin{array}{l}\text { Peripheral budding } \\
\text { Absent to focal ( } \leq 10 \%) \\
\text { Diffuse }(>10 \%)\end{array}$ & $\begin{array}{l}10(52.6) \\
9(53.3)\end{array}$ & $\begin{array}{l}8(47.4) \\
7(46.7)\end{array}$ & 0.968 \\
\hline $\begin{array}{l}\text { Intraepithelial microabscess } \\
\text { Absent } \\
\text { Present }\end{array}$ & $\begin{array}{l}9(47.4) \\
10(52.6)\end{array}$ & $\begin{array}{l}3(20.0) \\
12(80.0)\end{array}$ & 0.152 \\
\hline $\begin{array}{l}\text { T stage } \\
1 \\
2 \\
3\end{array}$ & $\begin{array}{l}7(36.8) \\
7(36.8) \\
5(26.3)\end{array}$ & $\begin{array}{l}3(20.0) \\
9(60.0) \\
3(20.0)\end{array}$ & 0.679 \\
\hline $\begin{array}{l}\text { AJCC stage } \\
\text { I, II } \\
\text { III, IV }\end{array}$ & $\begin{array}{l}11(57.9) \\
8(42.1)\end{array}$ & $\begin{array}{l}13(86.7) \\
2(13.3)\end{array}$ & 0.128 \\
\hline
\end{tabular}

HPV, human papilloma virus; HPF, high-power field; WD, well-differentiated; MD, moderately differentiated; PD, poorly differentiated; AJCC, the American Joint Committee on Cancer; LN, lymph node; PelN, penile intraepithelial neoplasia 


\begin{tabular}{|c|c|c|c|}
\hline Parameters & $\begin{array}{l}\text { TERT-p wild } \\
\mathrm{N}=19\end{array}$ & $\begin{array}{l}\text { TERT-p mutant } \\
\mathrm{N}=15\end{array}$ & P-value \\
\hline LN or distant metastases & $10(52.6)$ & $14(93.3)$ & 0.020 \\
\hline $\begin{array}{l}\text { Absent } \\
\text { Present }\end{array}$ & $9(47.4)$ & $1(6.7)$ & \\
\hline Tumor size $(\mathrm{cm})$ & $12(63.2)$ & $4(26.7)$ & 0.045 \\
\hline $\begin{array}{l}\leq 3 \\
>3\end{array}$ & $7(36.8)$ & $11(73.3)$ & \\
\hline \multicolumn{3}{|l|}{ Mean \pm SD } & 0.560 \\
\hline PelN & $7(36.8)$ & $13(86.7)$ & 0.005 \\
\hline $\begin{array}{l}\text { Non-HPV-related type } \\
\text { HPV-related type }\end{array}$ & $12(63.2)$ & $2(13.3)$ & \\
\hline $\begin{array}{l}\text { HPV, human papilloma vir } \\
\text { differentiated; PD, poorly } \\
\text { node; PelN, penile intraepi }\end{array}$ & $\begin{array}{l}\text { r field; WD, w } \\
\text {, the Americe }\end{array}$ & $\begin{array}{l}\text { entiated; MD, mc } \\
\text { Committee on C }\end{array}$ & N, lymph \\
\hline
\end{tabular}

\section{Correlation of TERT mutation status with $\mathrm{p} 16^{\text {INK4a }}$ and MIB-1 immunohistochemistry}

p16 ${ }^{\text {INK4a }}$ positivity was more frequent in TERT-p wild-type tumors $(12 / 19,63.2 \%)$ than in TERT-p mutant tumors $(1 / 15,6.7 \% ; p=0.001)$, which is consistent with the above result that TERT-p mutations were more frequent in non-HPV-related type than in HPV-related type penile SCC. In addition, the MIB-1 labeling index was significantly higher in TERT-p wild-type tumors $(45.26 \pm 19.38)$ than in TERT-p mutant tumors (31.80 $\pm 11.89)(p=0.014)$ (Fig. 2).

\section{Effects of TERT-p mutations on prognosis of patients with penile SCC}

We performed a power analysis to estimate the adequacy of sample size for Cox regression analysis in our study and a sample size of 34 subjects (wild group $=19$, mutant group $=15$ ) was optimally decided with $94.90 \%$ statistical power, a significance level of $p<0.05$, and the hazard ratio $=0.101(=1 / 9.86)$. As shown in Fig. 3, patients with TERT-p-mutated tumors showed significantly longer DFS compared with that of patients with TERT-p wild-type tumors $(p=0.009)$. However, there was no difference in OS between patients with TERT-p-mutated and wild-type tumors (see Additional file 1). A significant positive correlation between TERT-p mutation and DFS was confirmed by the univariate Cox regression analysis (hazard ratio $0.10,95 \% \mathrm{Cl} 0.01-0.82$ ). However, in the multivariate Cox regression analysis, TERT-p mutation status was not an independent factor affecting DFS (Table 4). 
Table 4

Disease-free survival univariate and multivariate Cox regression analysis in patients with penile squamous cell carcinoma

\begin{tabular}{|c|c|c|c|c|}
\hline \multirow[t]{3}{*}{ Variable } & \multicolumn{4}{|l|}{ Disease-free survival } \\
\hline & \multicolumn{2}{|l|}{ Univariate } & \multicolumn{2}{|l|}{ Multivariate } \\
\hline & $\mathrm{HR}(95 \% \mathrm{Cl})$ & $\begin{array}{l}\mathrm{P}- \\
\text { value }\end{array}$ & $\mathrm{HR}(95 \% \mathrm{Cl})$ & $\begin{array}{l}P \text { - } \\
\text { value }\end{array}$ \\
\hline $\begin{array}{l}\text { Histologic grade (WD vs } M \text { to } \\
\text { PD) }\end{array}$ & $3.01(0.37-24.20)$ & 0.301 & & \\
\hline Stage (I, II vs III, IV) & $\begin{array}{l}29.37(3.58- \\
240.87)\end{array}$ & 0.002 & $\begin{array}{l}179.50(5.37- \\
5997.0)\end{array}$ & 0.004 \\
\hline $\begin{array}{l}\text { Subtype (HPV vs non-HPV } \\
\text { related) }\end{array}$ & $0.50(0.13-1.89)$ & 0.311 & & \\
\hline LV invasion & $6.02(1.24-29.25)$ & 0.026 & $0.05(0.0-0.94)$ & 0.046 \\
\hline Perineural invasion & $4.39(1.17-16.46)$ & 0.028 & $3.65(0.66-20.13)$ & 0.137 \\
\hline Necrosis & $4.67(1.17-16.46)$ & 0.031 & $2.33(0.46-11.77)$ & 0.308 \\
\hline Mitotic figure ( $\leq 8$ vs $>8$ (/HPF)) & $2.80(0.74-10.55)$ & 0.128 & & \\
\hline MIB-1 LI $(\leq 40$ vs $>40)$ & $1.99(0.53-7.50)$ & 0.308 & & \\
\hline p16 INK4a positivity & $2.70(0.71-10.28)$ & 0.147 & & \\
\hline TERT-p (wild vs mutant) & $0.10(0.01-0.82)$ & 0.032 & $0.37(0.03-4.10)$ & 0.417 \\
\hline
\end{tabular}

\section{Discussion}

We here provide the first report of TERT-p mutation and its clinicopathologic significance in penile SCC. TERT-p mutations were detected at a high frequency (48.6\%) in penile SCC, which, to our knowledge, are the most frequent mutations in penile SCC described to date [34]. Indeed, the majority of recurrent mutations reported in penile SCC are of low incidence (less than 10\%) [34,35]. Notably, of the 18 cases with TERT-p mutations, 14 were c.-146 C > T and three were c.-124 C > T, which are known as mutation hotspots that have been reported as the most common recurrent mutations in various organs and tend to be mutually exclusive, with two exceptions in which both mutations were identified in two cases of breast cancer [24]. The remaining TERT-p mutation detected in our study was c.-124C $>\mathrm{A}$, which was found in both an excision and penectomy specimen of the same patient and was the only case of sarcomatoid carcinoma in our cohort. Histologically, the transitional area from conventional SCC to sarcomatoid carcinoma was included in this sarcomatoid carcinoma case. The c. $-124 \mathrm{C}>$ A mutation was previously 
reported in one mammary phyllodes tumor, as well as in urothelial carcinoma, hepatocellular carcinoma, and glioma [36].

Notably, all the three CIS cases included in our study harbored TERT-p mutations, suggesting that this mutation might be an early event of tumorigenesis in penile SCC. In line with this finding, TERT-p mutations were found at an early stage in urothelial cancer [25]. In addition, Lin et al. [37] found a TERT-p mutation in half of the periocular in situ SCC cases examined, and suggested that these mutations occur in the intraepithelial stage before the invasion of cancer cells.

The mutation rate of TERT-p in cutaneous SCC, which was used as a positive control, is concordant with previous reports [20]. Cheng et al. [23] evaluated TERT-p mutations in SCCs from different anatomic sites, finding a mutation rate of $70 \%$ for each of skin and urinary bladder SCCs, but only $20 \%$ for head and neck SCC, and no TERT-p mutations were identified in uterine cervix and lung cancer. The authors suggested that this finding supports a hypothesis of different carcinogenesis mechanisms of SCCs from different anatomic sites. Penile SCC shows a similar frequency of TERT-p mutations to that reported for cutaneous SCC or urothelial cancer.

Although we did not investigate germline mutations using matched blood samples of the patients, the absence of germline mutations in TERT-p in the 1000 Genomes database and in various studies on TERTp mutations using paired tumor and normal samples supports the possibility that the TERT-p mutations found in this study are likely somatic mutations $[12,13,38,39]$. ETS transcription factors, whose binding sites are generated within the promoter region through TERT-p mutations, are upregulated by the mitogenactivated protein kinase (MAPK) pathway; therefore, TERT-p mutations may be associated with mutations in genes involved in the MAPK pathway [12]. Indeed, tumors harboring TERT-p mutation at high frequency, such as melanoma, thyroid papillary carcinoma, and glioma, are also well known for a high frequency of BRAF mutation. Furthermore, significant coexistence of TERT-p and BRAF mutations, and their associations with adverse clinicopathological factors have been reported in some tumors, including papillary thyroid carcinoma and melanoma, suggesting that these coexisting mutations reflect a unique mechanism to upregulate the expression of TERT, cooperatively contributing to the aggressiveness of these tumors $[40,41]$. Likewise, we speculated that other mutations might coexist and act cooperatively with TERT-p mutations in penile SCC.

There have been only a few studies conducted on genetic alterations in penile SCC, including data obtained through whole-exome sequencing [34,35]. In general, the detection rates are low in all cases (detection rates of 3-9\%), the main mutated genes identified in penile SCC include KRAS, HRAS, NRAS, and PIK3CA, which are involved in the MAPK pathway $[4,34,35,42]$. BRAF mutation was also described in 2 out of 65 penile SCCs examined in one study, but the mutational status of TERT-p was not investigated in that cohort [34]. Therefore, further studies on mutations coexisting with TERT-p and their significance are needed to obtain deeper understanding of the roles of TERT-p mutations in penile carcinogenesis. 
Penile SCCs are pathologically divided into two groups, which are HPV-related and non-HPV-related. The key oncogenic mechanism of HPV in humans is its ability to reactivate telomerase, which largely involves the E6 protein of HR-HPV. E6 protein directly binds to hTERT and telomeric DNA or participates in the epigenetic and post-transcriptional regulation of hTERT [43, 44]. By contrast, E7 protein can maintain telomere length by the alternative lengthening of the telomerase pathway, irrespective of hTERT. A particularly interesting finding of this study was the much higher frequency of TERT-p mutation in nonHPV-related type of penile SCC, based on both histologic classification and p16 ${ }^{\text {INK4a }}$ immunoreactivity. Although we did not investigate the presence of HPV DNA, p16 ${ }^{\text {INK4a }}$ immunostaining has been established and widely used as a surrogate marker for transcriptionally active HR-HPV [6, 32]. TERT-p mutation was found in only 1 of 12 cases with p $16^{\text {INK4a }}$ positivity. In contrast, 14 of the $22(63.6 \%)$ cases showing negative immunoreactivity to $\mathrm{p} 16^{\mathrm{INK} 4 \mathrm{a}}$ harbored a TERT-p mutation. Similarly, the presence of differentiated PeIN, which is known to be a non-HPV-related type of PeIN in the adjacent mucosa, also correlated with TERT-p mutation in this study. These results suggest two major pathogenetic pathways of penile SCC that differ not only with respect to the relation to HPV but also with respect to the underlying molecular mechanism, with different mechanisms of telomerase activation. We speculate that in HPVrelated penile SCC, telomerase is activated by HPV E6 in the absence of TERT-p mutation, whereas mutations of TERT-p might play a role in the mechanism of telomerase activation in non-HPV-related penile cancer.

Based on this assumption, TERT-p mutation is suggested as a new potential therapeutic target in nonHPV-related cancer. Although penile cancer is typically divided into two distinct groups according to clinicopathologic features and its relation with HPV, there is no difference in the treatment of these different types, which is mainly due to the low prevalence and resulting limited data to understand the detailed mechanisms for targeted therapy. In addition, HPV-related cancer is known to respond better to radiation or chemoradiation therapy and shows a more favorable clinical course than non-HPV-related cancer [33]. Therefore, further studies are needed to validate our assumption and help to develop targeted therapies for penile carcinoma, especially for the non-HPV-related type.

As mentioned above, several previous studies have shown associations between TERT-p mutations and adverse clinicopathologic parameters or poor prognosis in various types of human cancers, including thyroid papillary carcinoma, melanoma, bladder cancer, and glioma [27, 29, 30, 45-47], which was the main motivation for the present study. However, in contrast to these previous reports, we found a correlation between TERT-p mutation with favorable clinicopathologic parameters in penile SCC, including a low histologic grade, low mitotic count, absence of necrosis, and low MIB-1 index. These results are in line with the fact that TERT-p mutations were more frequently detected in non-HPV-related tumors, which are generally low-grade tumors with low mitotic activities [48]. Similarly, the tumors in nonHPV-related penile SCC tend to be larger than those in the HPV-related type, which may explain the correlation between TERT-p mutant type and larger tumor size. Furthermore, the presence of TERT-p mutation was associated with a lower risk of lymph node or distant metastasis, and these patients had a significantly longer DFS than that of patients without TERT-p mutation based on Kaplan-Meier and log- 
rank analysis. In the univariate Cox proportional hazard model, the presence of TERT-p mutation was a significant factor for predicting longer DFS, but this significant effect was not maintained in the multivariate analysis.

Given the very low incidence of penile carcinoma, this study represents a relatively large series; nevertheless, the limitation of this study is its relatively small sample size. Therefore, further investigations in larger cohorts of patients and in vitro studies are needed to validate our results, and our results can offer new research directions into the pathogenetic mechanisms of this rare disease.

\section{Conclusion}

Our study shows TERT-p mutations are the most frequent somatic mutations in penile SCC reported to date. In addition, TERT-p mutations are far more frequent in non-HPV-related penile SCC based on both histological classification and p16 $16^{\text {NK4a }}$ immunopositivity and are associated with favorable histologic parameters, indicating that in case of non-HPV-related penile SCC, TERT-p mutations may have a role in tumorigenesis distinct from HPV-related penile SCC. This finding provides supporting evidence that nonHPV-related and HPV-related penile SCC necessitate different targeted treatments.

\section{Abbreviations}

(h)TERT

(human) Telomerase reverse transcriptase

HPV

human papillomavirus

SCC

squamous cell carcinoma

HPV-HR

high-risk type human papillomavirus

TERT-p

Telomerase reverse transcriptase promoter

CIS

carcinoma in situ

PCR

Polymerase chain reaction

ETS

E-twenty-six

PeIN

penile intraepithelial neoplasia

DFS

disease-free survival

OS 
overall survival

MAPK

mitogen-activated protein kinase

\section{Declarations}

\section{Ethics approval and consent to participate}

This study was approved by the Institutional Review Board of Ajou University School of Medicine. (AJIRM-BMR-KSP-17-305).

\section{Consent for publication}

Not applicable

\section{Availability of data and materials}

The datasets used and/or analysed during the current study are available from the corresponding author on reasonable request.

\section{Competing interests}

The authors declare that they have no competing interests.

\section{Funding}

This work was supported by the new faculty research fund of Ajou University School of Medicine.

\section{Author's contributions}

SK wrote the manuscript. JEK and NHC performed the histologic examination. JH and JK analyzed the immunohistochemical results. SJK, SHC, and SIK collected the clinical data. JSK and BP performed the statistical analyses. JEK designed the study and supervised the experiments. All authors read and approved the final manuscript.

\section{Acknowledgements}

We would like to thank Dr. Yoon Jin Cha for providing sample material, and Ji Young Yoon and Se Hwa Son for their technical support.

\section{References}

1. Rubin MA, Kleter B, Zhou M, Ayala G, Cubilla AL, Quint WG et al. Detection and typing of human papillomavirus DNA in penile carcinoma: evidence for multiple independent pathways of penile carcinogenesis. Am J Pathol. 2001;159:1211-1218. 
2. Suarez-Bonnet A, Willis C, Pittaway R, Smith K, Mair T, Priestnall SL. Molecular carcinogenesis in equine penile cancer: A potential animal model for human penile cancer. Urol Oncol. 2018; 36:532. e9-532. e18.

3. Mannweiler S, Sygulla S, Winter E, Regauer S. Two major pathways of penile carcinogenesis: HPVinduced penile cancers overexpress p16ink4a, HPV-negative cancers associated with dermatoses express p53, but lack p16ink4a overexpression. J Am Acad Dermatol. 2013;69:73-81.

4. Spiess PE, Dhillon J, Baumgarten AS, Johnstone PA, Giuliano AR. Pathophysiological basis of human papillomavirus in penile cancer: Key to prevention and delivery of more effective therapies. CA Cancer J Clin. 2016;66:481-495.

5. Cubilla AL, Amin MB, Ayala A, Ayala G, Chaux A, Corbishley C et al. Tumors of the penis. In: Holger Moch, Peter A. Humphrey, Thomas M. Ulbright, Victor E. Reuter, editors. Who classification of tumors of the urinary system and male genital organs. Lyon, France: IARC Press, 2016. p.260-279.

6. Aumayr K, Susani M, Horvat R, Wrba F, Mazal P, Klatte T et al. P16INK4A immunohistochemistry for detection of human papilloma virus-associated penile squamous cell carcinoma is superior to in-situ hybridization. Int J Immunopathol Pharmacol. 2013;26:611-620.

7. Baudino TA. Targeted Cancer Therapy: The Next Generation of Cancer Treatment. Curr Drug Discov Technol. 2015;12:3-20.

8. Kim JW, Kim YS, Ko WJ, Choi YD, Hong SJ, Chung BH et al. Prognostic Factors of Penile Cancer and the Efficacy of Adjuvant Treatment after Penectomy: Results from a Multi-institution Study. J Korean Med Sci. 2018;33:e233.

9. Vinagre J, Pinto V, Celestino R, Reis M, Populo H, Boaventura P et al. Telomerase promoter mutations in cancer: an emerging molecular biomarker? Virchows Arch. 2014;465:119-133.

10. Gunes C, Rudolph KL. The role of telomeres in stem cells and cancer. Cell. 2013;152:390-393.

11. Kyo S, Takakura M, Fujiwara T, Inoue M. Understanding and exploiting hTERT promoter regulation for diagnosis and treatment of human cancers. Cancer Sci. 2008;99:1528-1538.

12. Horn S, Figl A, Rachakonda PS, Fischer C, Sucker A, Gast A et al. TERT promoter mutations in familial and sporadic melanoma. Science. 2013;339:959-961.

13. Huang FW, Hodis E, Xu MJ, Kryukov GV, Chin L, Garraway LA. Highly recurrent TERT promoter mutations in human melanoma. Science. 2013;339:957-959.

14. Liu X, Bishop J, Shan Y, Pai S, Liu D, Murugan AK et al. Highly prevalent TERT promoter mutations in aggressive thyroid cancers. Endocr Relat Cancer. 2013;20:603-610.

15. Arita H, Narita Y, Fukushima S, Tateishi K, Matsushita Y, Yoshida A et al. Upregulating mutations in the TERT promoter commonly occur in adult malignant gliomas and are strongly associated with total 1p19q loss. Acta Neuropathol. 2013;126:267-276.

16. Allory Y, Beukers W, Sagrera A, Flandez M, Marques M, Marquez M et al. Telomerase reverse transcriptase promoter mutations in bladder cancer: high frequency across stages, detection in urine, and lack of association with outcome. Eur Urol. 2014;65:360-366. 
17. Liu X, Wu G, Shan Y, Hartmann C, von Deimling A, Xing M. Highly prevalent TERT promoter mutations in bladder cancer and glioblastoma. Cell Cycle. 2013;12:1637-1638.

18. Chen YL, Jeng YM, Chang CN, Lee HJ, Hsu HC, Lai PL et al. TERT promoter mutation in resectable hepatocellular carcinomas: a strong association with hepatitis $C$ infection and absence of hepatitis $B$ infection. Int J Surg. 2014;12:659-665.

19. Populo H, Boaventura P, Vinagre J, Batista R, Mendes A, Caldas R et al. TERT promoter mutations in skin cancer: the effects of sun exposure and X-irradiation. J Invest Dermatol. 2014;134:2251-2257.

20. Griewank KG, Murali R, Schilling B, Schimming T, Moller I, Moll I et al. TERT promoter mutations are frequent in cutaneous basal cell carcinoma and squamous cell carcinoma. PLoS One. 2013;8:e80354.

21. Scott GA, Laughlin TS, Rothberg PG. Mutations of the TERT promoter are common in basal cell carcinoma and squamous cell carcinoma. Mod Pathol. 2014;27:516-523.

22. van Nistelrooij AM, Zwarthoff EC, Post E, Lurkin I, van Marion R, Korpershoek E et al. Absence of TERT promoter mutations in esophageal adenocarcinoma. Int J Cancer. 2014;134:2014-2015.

23. Cheng KA, Kurtis B, Babayeva S, Zhuge J, Tantchou I, Cai D et al. Heterogeneity of TERT promoter mutations status in squamous cell carcinomas of different anatomical sites. Ann Diagn Pathol. 2015;19:146-148.

24. Huang FW, Hodis E, Xu MJ, Kryukov GV, Chin L, Garraway LAJS. Highly recurrent TERT promoter mutations in human melanoma. 2013;339:957-959.

25. Kinde I, Munari E, Faraj SF, Hruban RH, Schoenberg M, Bivalacqua T et al. TERT promoter mutations occur early in urothelial neoplasia and are biomarkers of early disease and disease recurrence in urine. Cancer Res. 2013;73:7162-7167.

26. Qu Y, Dang S, Wu K, Shao Y, Yang Q, Ji M et al. TERT promoter mutations predict worse survival in laryngeal cancer patients. Int J Cancer. 2014;135:1008-1010.

27. Chen C, Han S, Meng L, Li Z, Zhang X, Wu A. TERT promoter mutations lead to high transcriptional activity under hypoxia and temozolomide treatment and predict poor prognosis in gliomas. PLoS One. 2014;9:e100297.

28. Melo M, da Rocha AG, Vinagre J, Batista R, Peixoto J, Tavares $C$ et al. TERT promoter mutations are a major indicator of poor outcome in differentiated thyroid carcinomas. J Clin Endocrinol Metab. 2014;99:E754-765.

29. Griewank KG, Murali R, Puig-Butille JA, Schilling B, Livingstone E, Potrony M et al. TERT promoter mutation status as an independent prognostic factor in cutaneous melanoma. J Natl Cancer Inst. 2014;106.

30. Simon M, Hosen I, Gousias K, Rachakonda S, Heidenreich B, Gessi M et al. TERT promoter mutations: a novel independent prognostic factor in primary glioblastomas. Neuro Oncol. 2015;17:45-52.

31. Shimizu S, Miyazaki A, Sonoda T, Koike K, Ogi K, Kobayashi Jl et al. Tumor budding is an independent prognostic marker in early stage oral squamous cell carcinoma: With special reference to the mode of invasion and worst pattern of invasion. PLoS One. 2018;13:e0195451. 
32. Cubilla AL, Lloveras B, Alejo M, Clavero O, Chaux A, Kasamatsu E et al. Value of p16(INK)(4)(a) in the pathology of invasive penile squamous cell carcinomas: A report of 202 cases. Am J Surg Pathol. 2011;35:253-261.

33. Eich ML, Del Carmen Rodriguez Pena M, Schwartz L, Granada CP, Rais-Bahrami S, Giannico G et al. Morphology, p16, HPV, and outcomes in squamous cell carcinoma of the penis: a multi-institutional study. Hum Pathol. 2019. https://doi.org/10.1016/j.humpath.2019.09.013

34. Ferrandiz-Pulido C, Hernandez-Losa J, Masferrer E, Vivancos A, Somoza R, Mares R et al. Identification of somatic gene mutations in penile squamous cell carcinoma. Genes Chromosomes Cancer. 2015;54:629-637.

35. Wang Y, Wang K, Chen Y, Zhou J, Liang Y, Yang X et al. Mutational landscape of penile squamous cell carcinoma in a Chinese population. Int J Cancer. 2019;145:1280-1289.

36. Yoshida M, Ogawa R, Yoshida H, Maeshima A, Kanai Y, Kinoshita T et al. TERT promoter mutations are frequent and show association with MED12 mutations in phyllodes tumors of the breast. $\mathrm{Br} \mathrm{J}$ Cancer. 2015;113:1244-1248.

37. Lin SY, Liao SL, Hong JB, Chu CY, Sheen YS, Jhuang JY et al. TERT promoter mutations in periocular carcinomas: implications of ultraviolet light in pathogenesis. Br J Ophthalmol. 2016;100:274-277.

38. Abecasis GR, Auton A, Brooks LD, DePristo MA, Durbin RM, Handsaker RE et al. An integrated map of genetic variation from 1,092 human genomes. Nature. 2012;491:56-65.

39. Killela PJ, Reitman ZJ, Jiao Y, Bettegowda C, Agrawal N, Diaz LA, Jr. et al. TERT promoter mutations occur frequently in gliomas and a subset of tumors derived from cells with low rates of self-renewal. Proc Natl Acad Sci U S A. 2013;110:6021-6026.

40. Macerola E, Loggini B, Giannini R, Garavello G, Giordano M, Proietti A et al. Coexistence of TERT promoter and BRAF mutations in cutaneous melanoma is associated with more clinicopathological features of aggressiveness. Virchows Arch. 2015;467:177-184.

41. Xing M, Liu R, Liu X, Murugan AK, Zhu G, Zeiger MA et al. BRAF V600E and TERT promoter mutations cooperatively identify the most aggressive papillary thyroid cancer with highest recurrence. $J$ Clin Oncol. 2014;32:2718-2726.

42. Silva Amancio AM, Cunha IW, Neves JI, Quetz JD, Carraro DM, Rocha RM et al. Epidermal growth factor receptor as an adverse survival predictor in squamous cell carcinoma of the penis. Hum Pathol. 2017;61:97-104.

43. Katzenellenbogen RA. Activation of telomerase by HPVs. Virus Res. 2017;231:50-55.

44. Katzenellenbogen R. Telomerase Induction in HPV Infection and Oncogenesis. Viruses. 2017; 9:E180.

45. Nasirden A, Saito T, Fukumura Y, Hara K, Akaike K, Kurisaki-Arakawa A et al. In Japanese patients with papillary thyroid carcinoma, TERT promoter mutation is associated with poor prognosis, in contrast to BRAF (V600E) mutation. Virchows Arch. 2016;469:687-696.

46. Wang K, Liu T, Ge N, Liu L, Yuan X, Liu J et al. TERT promoter mutations are associated with distant metastases in upper tract urothelial carcinomas and serve as urinary biomarkers detected by a sensitive castPCR. Oncotarget. 2014;5:12428-12439. 
47. Lee S, Barnhill RL, Dummer R, Dalton J, Wu J, Pappo A et al. TERT Promoter Mutations Are Predictive of Aggressive Clinical Behavior in Patients with Spitzoid Melanocytic Neoplasms. Sci Rep. 2015;5:11200.

48. Steinestel J, Al Ghazal A, Arndt A, Schnoeller TJ, Schrader AJ, Moeller P et al. The role of histologic subtype, p16(INK4a) expression, and presence of human papillomavirus DNA in penile squamous cell carcinoma. BMC Cancer. 2015;15:220.

\section{Figures}



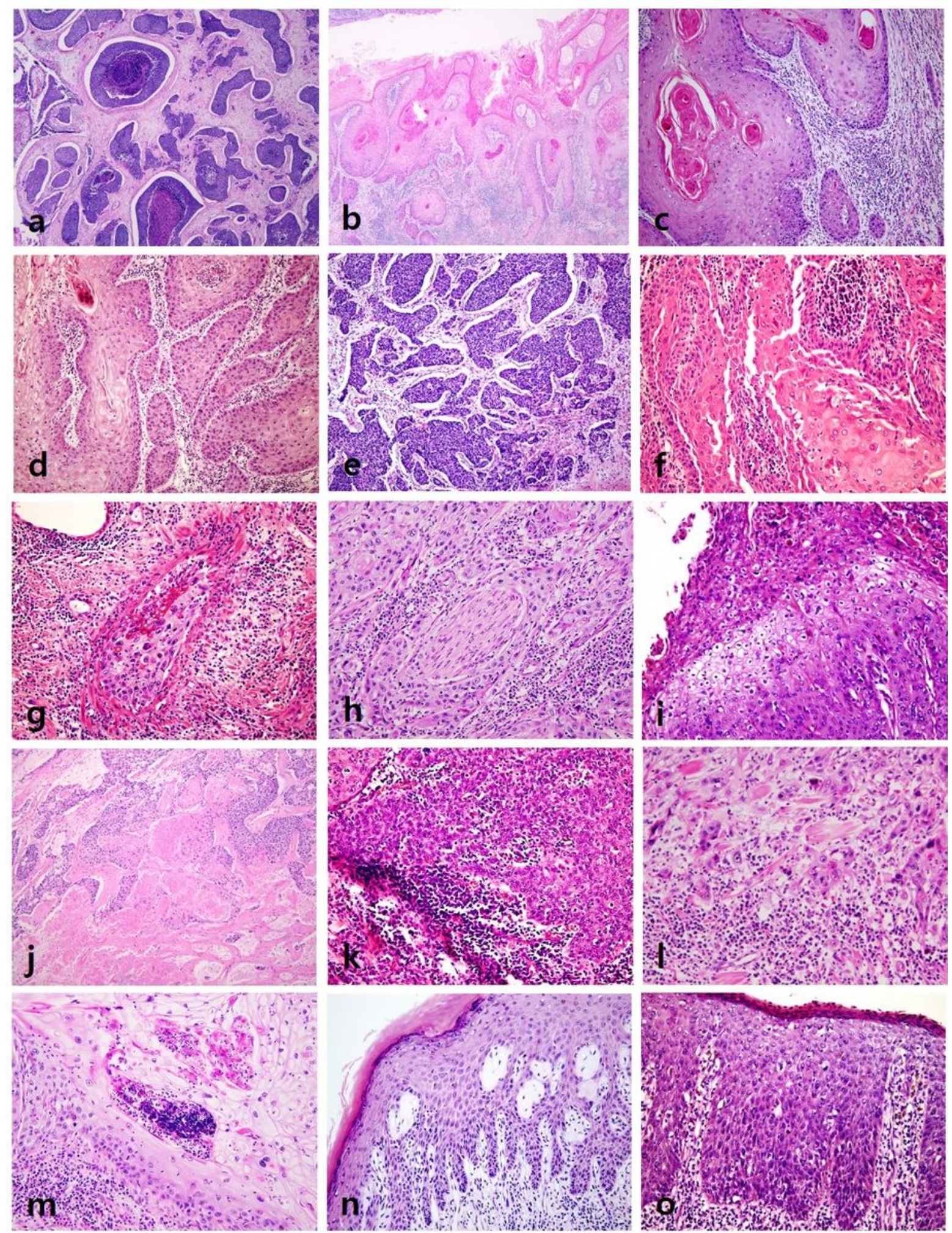

\section{Figure 1}

Representative images of histologic parameters. (a) Basaloid carcinoma (HPV-related type). (b) Papillary carcinoma (non-HPV-related type). (c-e) Histologic grade: (c) well-differentiated, (d) moderately differentiated, (e) poorly differentiated. (f) Acantholysis. (g) Lymphovascular invasion. (h) Perineural invasion. (i) Koilocytosis. (j) Necrosis. (k) Tumor-infiltrating lymphocytes: brisk (I) Peripheral budding. (m) 
Intraepithelial microabscess (n). Penile intraepithelial neoplasia, differentiated (Non-HPV-related) (o) Penile intraepithelial neoplasia, HPV-related.
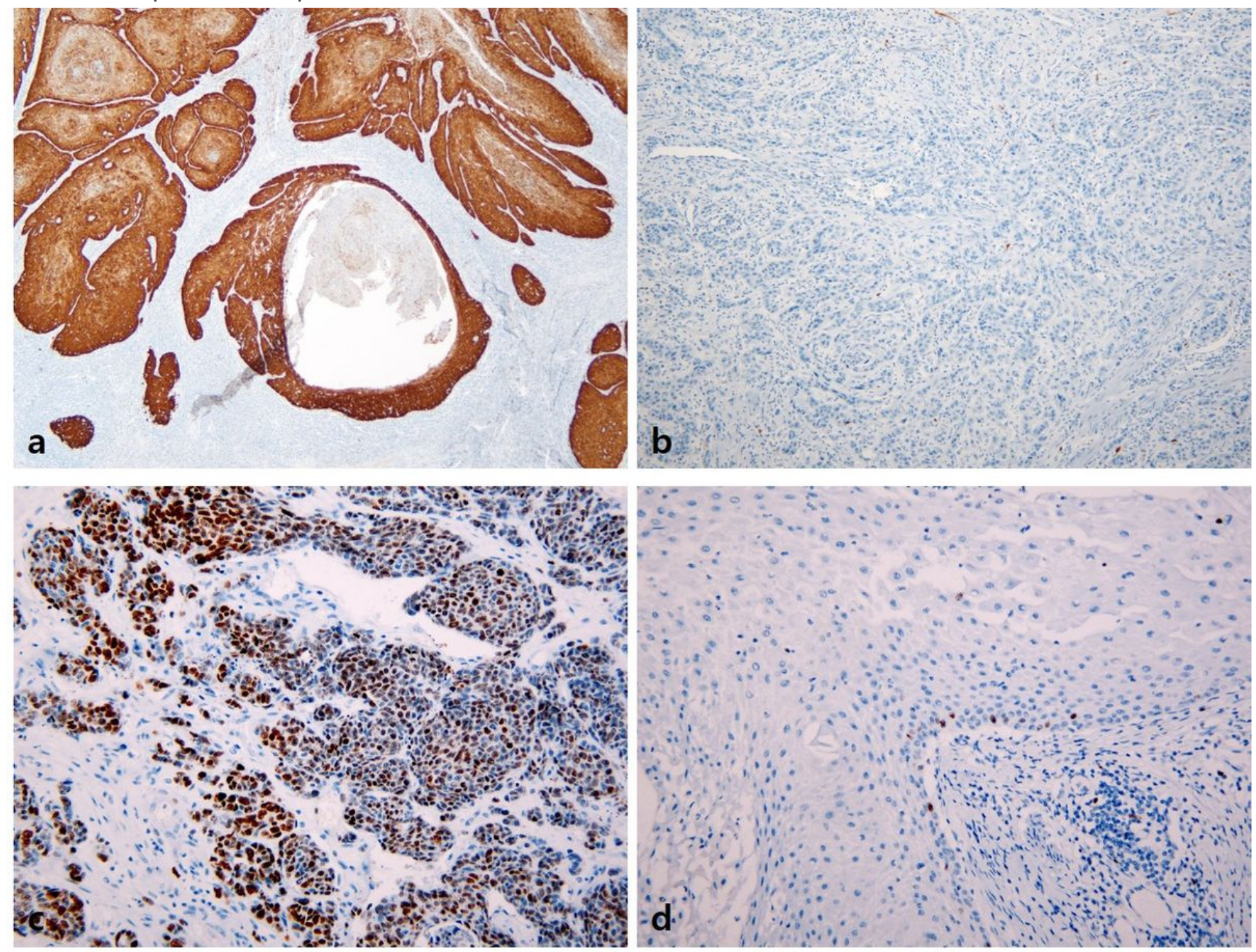

Figure 2

Immunohistochemical staining for $\mathrm{p} 16$ and MIB-1 in penile SCC. (a) Diffuse strong positivity for p16INK4a in TERT-p wild-type penile SCC. (b) p16 INK4a negativity in TERT-p-mutated penile SCC. (c) high MIB-1 labeling index. (d) low MIB-1 labeling index. 


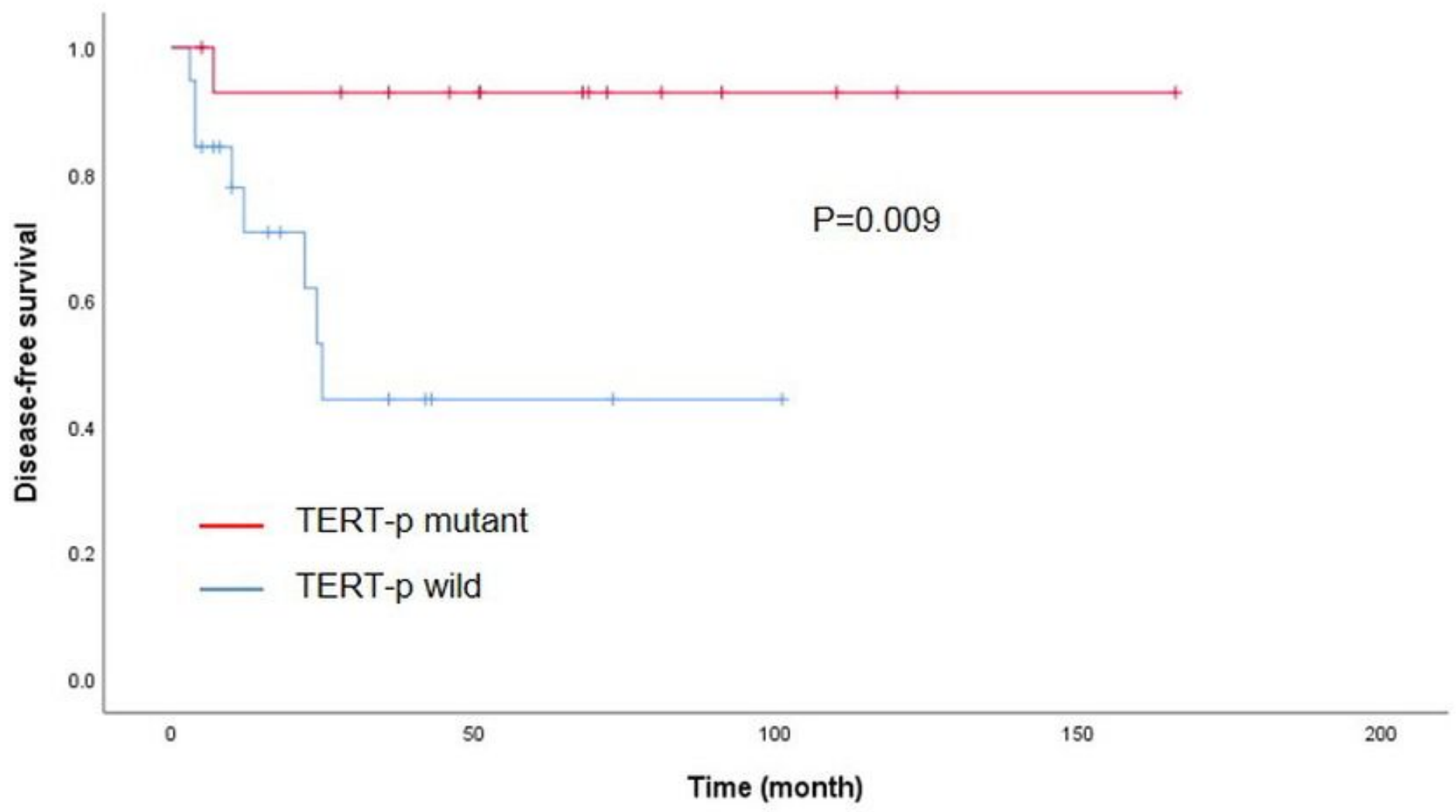

Figure 3

Kaplan-Meir analysis of the impact of TERT-p mutation on disease-free survival of patients with penile SCC.

\section{Supplementary Files}

This is a list of supplementary files associated with this preprint. Click to download.

- Additionalfile1.docx

- Additionalfile1.docx

- Additionalfile1.docx 